\title{
Herbaceous species diversity patterns across various treatments of herbivory and fire along the sodic zone of the Nkuhlu exclosures, Kruger National Park
}

\begin{tabular}{|c|c|}
\hline \multicolumn{2}{|c|}{$\begin{array}{l}\text { Authors: } \\
\text { Helga van Coller }^{1} \\
\text { Frances Siebert }^{1} \\
\text { Stefan J. Siebert }\end{array}$} \\
\hline \multicolumn{2}{|c|}{$\begin{array}{l}\text { Affiliations: } \\
{ }^{1} \text { School of Biological } \\
\text { Sciences, North-West } \\
\text { University, South Africa }\end{array}$} \\
\hline \multicolumn{2}{|c|}{$\begin{array}{l}\text { Correspondence to: } \\
\text { Helga van Coller }\end{array}$} \\
\hline \multicolumn{2}{|c|}{$\begin{array}{l}\text { Email: } \\
\text { 21119465@nwu.ac.za }\end{array}$} \\
\hline \multicolumn{2}{|c|}{$\begin{array}{l}\text { Postal address: } \\
\text { Private Bag X6001, } \\
\text { Potchefstroom 2520, } \\
\text { South Africa }\end{array}$} \\
\hline \multicolumn{2}{|c|}{$\begin{array}{l}\text { Dates: } \\
\text { Received: } 12 \text { Sept. } 2012 \\
\text { Accepted: } 21 \text { Dec. } 2012 \\
\text { Published: } 18 \text { Mar. } 2013\end{array}$} \\
\hline \multicolumn{2}{|c|}{$\begin{array}{l}\text { How to cite this article: } \\
\text { Van Coller, H., Siebert, } \\
\text { F. \& Siebert, S.J., 2013, } \\
\text { 'Herbaceous species diversity } \\
\text { patterns across various } \\
\text { treatments of herbivory and } \\
\text { fire along the sodic zone } \\
\text { of the Nkuhlu exclosures, } \\
\text { Kruger National Park', Koedoe } \\
55(1), \text { Art. \#1112, } 6 \text { pages. } \\
\text { http://dx.doi.org/10.4102/ } \\
\text { koedoe.v55i1.1112 }\end{array}$} \\
\hline \multicolumn{2}{|c|}{$\begin{array}{l}\text { Copyright: } \\
\text { C 2013. The Authors. } \\
\text { Licensee: AOSIS } \\
\text { OpenJournals. This wc } \\
\text { is licensed under the } \\
\text { Creative Commons } \\
\text { Attribution License. }\end{array}$} \\
\hline \multicolumn{2}{|l|}{ Read online: } \\
\hline 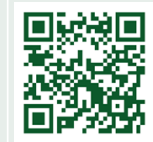 & $\begin{array}{l}\text { Scan this QR } \\
\text { code with your } \\
\text { smart phone or } \\
\text { mobile device } \\
\text { to read online. }\end{array}$ \\
\hline
\end{tabular}

Understanding relationships between large herbivores and plant species diversity in dynamic riparian zones is critical to biodiversity conservation. The Nkuhlu exclosures in the Kruger National Park (KNP) provided opportunity to investigate spatial heterogeneity patterns within riparian zones, as well as how these patterns are affected by fire and herbivory. A monitoring project was initiated to answer questions about the dynamics of the herbaceous layer and was aimed at determining, (1) whether there exists meaningful variance in herbaceous plant species richness and diversity across different treatments in the ecologically sensitive sodic zone and (2) whether an increase in herbaceous biomass, an artefact of herbivory and fire exclusion, suppresses herbaceous plant species diversity and richness. Herbaceous vegetation was sampled in two $1 \mathrm{~m}^{2}$ circular sub-plots in the eastern and western corners of 81 fixed plots. The biomass of each plot was estimated with a disc pasture meter (DPM) diagonally with the plot. DPM-readings were converted to $\mathrm{kg} / \mathrm{ha}$, according to the latest conversions for the Lowveld Savanna. Species richness and biomass showed significant variance across treatments, whereas no significant variation in herbaceous species diversity was perceived. Combined treatment of fire absence and herbivore presence contributed to higher forb species richness in the sodic zone. Biomass is significantly higher in fully fenced areas where herbivores are excluded, as opposed to the open and partially fenced areas. Although no significant variation was recorded for diversity across treatments, lowest diversity was recorded in the absence of all herbivores, especially in combination with fire treatment. Therefore herbivores are essential in sustaining herbaceous plant species richness in the sodic zone, whilst no significant results were found with regard to their effect on species diversity. Although statistically non-significant, fire seems to suppress species richness.

Conservation implications: This study could be used as framework to advance and develop science-based management strategies for, at least, the sodic zones of the KNP. Research in these exclosures will create better understanding of these landscapes, benefit ecosystem conservation planning of national parks and also provide valuable long-term information on key ecological processes.

\section{Introduction}

Sodic patches are often associated with footslopes of undulating granitic landscapes (Venter 1990) and are commonly referred to as 'nutrient hotspots' as they produce high quality forage (Grant \& Scholes 2006). Deep, duplex soil containing dispersed clay with a low infiltration capacity and high concentrations of nitrogen, phosphorus and sodium characterise sodic patches (Dye \& Walker 1980; Khomo \& Rogers 2005). Sodic soil is associated with reduced hydraulic conductivity as a result of the hyper-accumulation of exchangeable sodium and is prominent in landscapes derived from sodium-releasing parent material such as granite (Khomo \& Rogers 2005). Soil is considered 'sodic' when high concentrations of soluble salts prevail, which are dominated by sodium, the $\mathrm{pH}$ is greater than 8.5 and electrical conductivity is less than $4.0 \mathrm{dS} / \mathrm{m}$ (Tarasoff, Mallory-Smith \& Ball 2007). The level of sodium in soil is often reported as the sodium adsorption ratio (SAR). Soil is classified as sodic when the SAR is above 13; at levels below 13, sodium can cause deterioration of soil structure and problems with water infiltration (Davis, Waskom \& Bauder 2012).

Sodic patches form an integral part of savanna ecosystems because of the ecosystem services and functioning they provide, such as, (1) the accumulation of nutrients, (2) the provision of open spaces for predator vigilance and (3) the formation of wet season wallowing points (Khomo \& Rogers 2005). Furthermore, these key resource areas sustain animal body condition for dry season survival and support reproduction through nutritional benefits (Grant \& Scholes 2006). Despite their ecological significance, sodic patches are often considered as desolate land because of their disturbed appearance and low aesthetic value (Khomo \& Rogers 2005) caused by overgrazing, 
which, in turn, impacts on herbaceous species diversity, richness and biomass (Jacobs \& Naiman 2008).

Fire and herbivory are regarded as important ecosystem modifiers, especially in semi-arid southern African savannas, often acting together (Archibald et al. 2005). Fire and herbivory are considered as dominant mediators of vegetation change in the Kruger National Park (KNP) and interact strongly with rainfall unpredictability and prolonged droughts (Du Toit, Rogers \& Biggs 2003). The impact of fire and herbivory on herbaceous biomass dynamics is, however, poorly understood (Archibald et al. 2005; Jacobs \& Naiman 2008). The establishment of the Nkuhlu exclosures in the KNP in 2001 provided an opportunity to study the spatial and temporal heterogeneity patterns within and around riparian zones, as well as how these patterns are affected by herbivory and fire. By excluding these drivers from the system it is believed that their effects could be determined over time (O’Keefe \& Alard 2002).

Jacobs and Naiman (2008) were the first to report on the relationship between herbivory and species richness at the Nkuhlu exclosures. After 2 years of herbivory exclusion, a marked increase in standing biomass was recorded, along with lower species richness in the absence of herbivores. These patterns were, however, less significant along the sodic zone (Jacobs \& Naiman 2008). This article is therefore aimed at reporting on herbaceous plant species richness, diversity and biomass specifically along the sodic zone of the Nkuhlu exclosures after an additional 5-year cycle of herbivory and fire exclusion.

The objectives of this study were to test, (1) whether significant variation in herbaceous plant species diversity, richness and biomass could be detected across different combined treatments of herbivory and fire and (2) whether increasing biomass, an artefact of herbivory and fire exclusion, suppresses diversity and richness of herbaceous plant species in the sodic zone of the Nkuhlu exclosures.

\section{Study area}

The Nkuhlu large-scale long-term exclusion experiment $\left(24^{\circ} 58^{\prime} \mathrm{S}, 31^{\circ} 46^{\prime} \mathrm{E}\right)$ is situated on the northern bank of the Sabie River, approximately $18 \mathrm{~km}$ downstream from Skukuza (Siebert \& Eckhardt 2008). This semi-arid, subtropical savanna has two distinct seasons: a hot, sporadically wet growth season from October to April and a warm, dry, nongrowing season (Scogings et al. 2012). The mean annual rainfall is $561 \mathrm{~mm}$, whilst temperatures range from a mean minimum of $5.6^{\circ} \mathrm{C}$ in winter to a mean maximum of $32.6^{\circ} \mathrm{C}$ in the summer months. Crests and midslopes are characterised by coarse, shallow, sandy soil overlaying weathered rock, whilst footslopes below the seep-line are characterised by deep, duplex soil (Scogings et al. 2012; Siebert \& Eckhardt 2008). The duplex soil on footslopes is referred to as the sodic zone in this article.

On a national scale, the Nkuhlu exclosures are located within the Granite Lowveld vegetation unit (SVI 3) (Mucina \& Rutherford 2006). It is characterised by tall shrubland with few trees to moderately dense low woodland on deep sandy uplands. The dense herbaceous layer is dominated by the graminoids Aristida congesta, Digitaria eriantha and Panicum maximum. The riparian zone of the exclosures forms part of the Subtropical Alluvial vegetation unit (AZa 7), which is described by Mucina and Rutherford (2006) as having flat alluvial riverine terraces that supports a complex channel of flowing rivers and river-fed pans, marginal reed belts, as well as flooded grasslands, ephemeral herblands and riverine thickets.

The sodic zone plant community was described by Siebert and Eckhardt (2008) as Sporobolus nitens-Euclea divinorum Dry Sodic Savanna, covering roughly $23 \%$ of the total sampling area of the Nkuhlu exclosures. The sodic plant community supports contrasting vegetation and herbivore activities that differ from those found on upland savanna soil (Du Toit et al. 2003). It stretches across the exclosure fence lines and shows noticeable visual differences amongst herbivory and fire treatments. The diagnostic and dominant herbaceous species of the sodic community include forbs, such as Abutilon austroafricanum, Portulaca kermesina and Ocimum americanum, and graminoids, such as Chloris virgata, Enteropogon monostachyus and S. nitens (Siebert \& Eckhardt 2008).

\section{Methods}

\section{Experimental design and sampling}

The Nkuhlu exclosures comprise 139 ha of semi-arid savanna in the riparian zone of the Sabie River and consist of three herbivory treatments, each divided into a fire and no-fire treatment, hence six treatment combinations overall (Figure 1). The herbivory treatments consist of, (1) a partially fenced area of 44 ha that was designed to specifically exclude elephants (giraffes are also excluded because their body size), (2) an open, unfenced area of 25 ha (referred to as the 'control site') and (3) a fully fenced area of 70 ha, which was designed to exclude all herbivores larger than a hare (Siebert \& Eckhardt 2008).

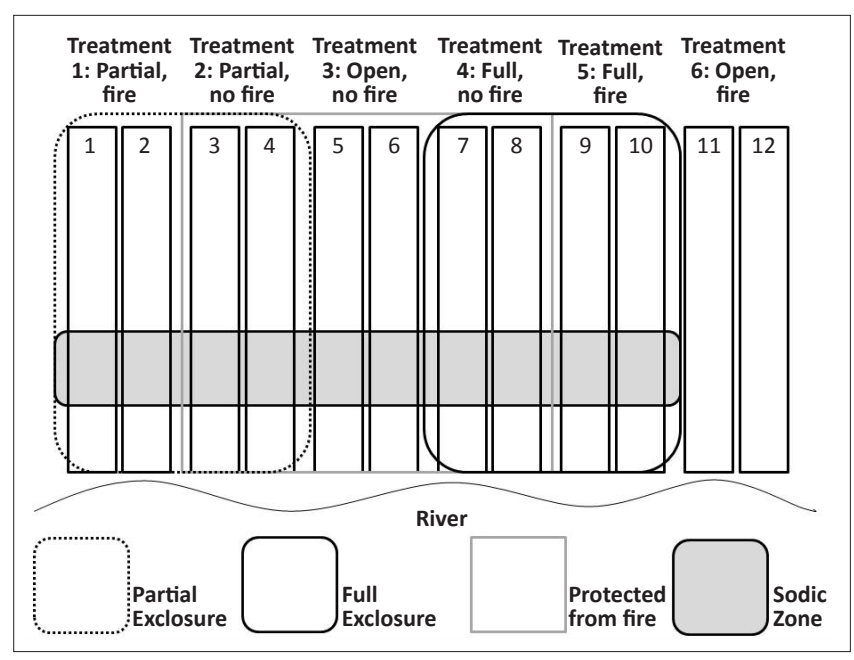

FIGURE 1: Experimental layout of 12 transects within six different fire and herbivory treatments of the Nkuhlu exclosures, Kruger National Park. Treatment 6 was excluded from this study to include sodic sites only. 
Vegetation of sodic soil is considered to be more palatable by large herbivores, particularly grazers and mixed feeders (intermediate feeders) than crest vegetation (Scogings 2011). Mammalian herbivores residing in the study area include: browsers - such as giraffe (Giraffa camelopardalis), black rhino (Diceros bicornis), greater kudu (Tragelaphus strepsiceros) and the scrub hare (Lepus saxatilis), grazers - such as Cape buffalo (Syncerus caffer), hippo (Hippopotamus amphibius), blue wildebeest (Connochaetes taurinus) and plains zebra (Equus quagga), and mixed or intermediate feeders - such as impala (Aepyceros melampus), African elephant (Loxodonta africana) and steenbok (Raphicerus campestris) (Scogings et al. 2012). The density of elephants in the study area fluctuates, but has been estimated and considered high at $0.5 \mathrm{~km}^{-2}-2.0 \mathrm{~km}^{-2}$ (Scogings et al. 2012).

Fire treatment of the Nkuhlu exclosures was dependant on whether the larger KNP burn blocks (fire management units) in which the exclosures lie were burned irrespective of the source and the actual extent of the fire. Fires occurred in October 2002 and August 2007.

Floristic sampling, which conformed to the guidelines stipulated in the field operations manual for herbivore and fire exclosures (O'Keefe \& Alard 2002), was conducted during the 2010 rainy season (i.e. October-March) (Van Wyk \& Fairall 1969) when plant cover was at its maximum and most plant species were present (Keller 2002). All treatments were sampled, although only data from the sodic zone were analysed for this study. As the sodic zone did not extend into the control site with fire, two transects could not be considered for floristic analyses. Each treatment of fire and/ or herbivory consisted of two permanent transects (Figure 1). Transects stretch from the river to the crest of the catena and run perpendicular to the river. Permanent transects were marked with metal droppers. Fixed plots were situated $5 \mathrm{~m}$ downstream from each transect dropper. The position of transects and plots were plotted on the vegetation map of the Nkuhlu exclosures (Siebert \& Eckhardt 2008) to identify plots that are representative of the sodic zone. The data of 81 fixed plots of $10 \mathrm{~m} \times 20 \mathrm{~m}$ (long side parallel to the river channel) within the sodic zone (Figure 2) were analysed.

Herbaceous vegetation was sampled in two $1 \mathrm{~m}^{2}$ circular subplots at the eastern (upland downstream) and western (river upstream) corners of each fixed plot respectively (Figure 2). Only herbaceous individuals rooted within the circle were recorded. Each living individual (forbs and grasses) was counted and all species names conform to Germishuizen and Meyer (2003). The biomass of each plot was estimated, by taking 10 readings along the diagonal of the plot, with a Lowveld Savanna-calibrated disc pasture meter (DPM) (Figure 2). These readings were converted to $\mathrm{kg} / \mathrm{ha}$ according to the latest conversion of DPM-readings to biomass for the Lowveld Savanna (Zambatis et al. 2006).

Two equations for DPM height groups ( $\leq 26 \mathrm{~cm}$ and $>26 \mathrm{~cm}$ ) were proposed by Zambatis et al. 2006: kg.ha-1 $=\left[31.7176\left(0.3218^{1 / x}\right) x^{0.2834}\right]^{2} r=0.9796 ;$

$r^{2}=0.951 ; p<0.0005$

[Eqn 1]

kg.ha ${ }^{-1}=\left[17.3543\left(0.9893^{x}\right) x^{0.5413}\right]^{2} r=0.948 ;$

$r^{2}=0.882 ; p<0.0005$

[Eqn 2]

where $x$ is the mean DPM height (in $\mathrm{cm}$ ) of a site.

Species richness is the number of species present in a defined area (Begon, Townsend \& Harper 2006). In this study, richness was considered as the number of species per circular sub-plot $\left(1 \mathrm{~m}^{2}\right)$. Species diversity was calculated for the plots with the Shannon-Wiener index of diversity $\left(\mathrm{H}^{\prime}\right)$, which is sensitive to both species richness and the number of individuals (abundance) per species (Keller 2002). The greater the number of species and the higher the evenness (proportion of each species), the higher the $\mathrm{H}^{\prime}$-value, which suggests that the diversity in the plot is high (Begon et al. 2006; Keller 2002). The function $H^{\prime}$ used in this study is:

$\mathrm{H}^{\prime}=-\sum\left(p_{\mathrm{i}} \cdot \ln p_{\mathrm{i}}\right) \ldots$

[Eqn 3]

where $p_{\mathrm{i}}$ is the relative abundance of the ith species. This index provides a rough measure of diversity, which is much less biased by sample size than species richness.

To test for significant variation in species diversity, richness and biomass of the herbaceous layer amongst the five different treatments of fire and herbivory, one-way analysis of variance (ANOVA) was applied to the data set in Statistica version 10 (2010). Where statistically significant results were obtained, post-hoc pair-wise comparisons of the treatments - using the Tukey unequal N HSD (honestly significant difference) test - were conducted.

\section{Results}

Analysis of variance (Table 1) for all variables revealed significant effects of herbivory, with or without fire, on both

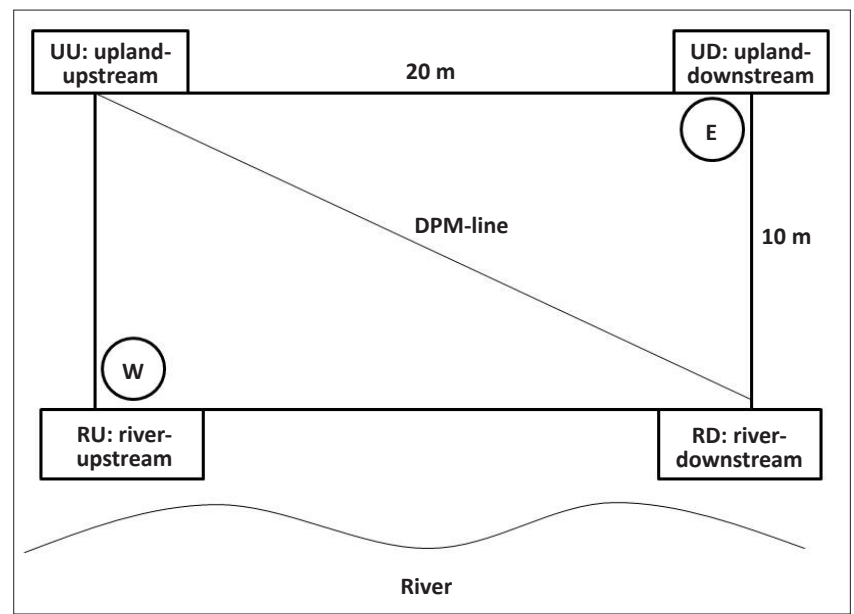

W, western corner; E, eastern corner; DPM, disc pasture meter.

FIGURE 2: Positioning of the $1 \mathrm{~m}^{2}$ sub-plots for herbaceous species sampling and the sampling line for disc pasture meter readings within a typical fixed plot along a transect at the Nkuhlu exclosures, Kruger National Park. The corners of each plot are permanently marked with metal droppers which represent a different position parallel to the Sabie River. 
TABLE 1: One-way analysis of variance of the mean values for herbaceous biomass and species richness and diversity across treatments along the sodic zone of the Nkuhlu exclosures, Kruger National Park.

\begin{tabular}{|c|c|c|c|c|c|c|}
\hline Response & Source & $d f$ & SS & MS & $F$ & $p$ \\
\hline \multirow[t]{2}{*}{ Biomass } & Treatment & 4 & 51135137.00 & 12783784.00 & 26.161340 & $<0.0001$ \\
\hline & s.e. & 76 & 37137528.00 & 488651.70 & 26.161340 & $<0.0001$ \\
\hline \multirow[t]{2}{*}{ Species richness } & Treatment & 4 & 2883.00 & 234.10 & 6.170180 & 0.0002 \\
\hline & s.e. & 76 & 2883.00 & 37.94 & 6.170180 & 0.0002 \\
\hline \multirow[t]{2}{*}{ Shannon-Wiener diversity index } & Treatment & 4 & 0.76 & 0.20 & 1.011267 & 0.4 \\
\hline & s.e. & 76 & 14.00 & 0.19 & 1.011267 & 0.4 \\
\hline
\end{tabular}

s.e., standard error; $d f$, degrees of freedom; SS, sum of squared differences; MS, mean square; $F$, whether variability within and between treatments is significantly different; $p$, $p$-values below a certain threshold indicates the significant differences between groups.

biomass $(p<0.0001)$ and species richness $(p=0.0002)$ across the different treatments, whilst the effects of herbivory, with or without fire, on species diversity was non-significant $(p=0.4)$.

Mean biomass ( $\mathrm{kg} / \mathrm{ha}$ ) varied significantly across treatments $(p=0.0001)$ (Table 1; Figure 3). As would be expected, mean biomass was highest in the fully fenced plots as a result of herbivore exclusion. In pair-wise comparisons of biomass means, significant differences were revealed between the control (i.e. open, no fire) site with unrestricted herbivory and the fully fenced area, both with (Tukey: $p<0.05$ ) and without fire (Tukey: $p<0.05)$ treatment. Furthermore, both of the partial herbivore treatments showed significant differences compared to both fully fenced herbivore exclusion treatments. Although the effect of fire seems secondary to herbivory, mean biomass was consistently lower in the fire treatments (Figure 3).

A total of 187 herbaceous plant species were recorded in the sodic zone of the Nkuhlu exclosures. Species richness varied significantly across the combinations of herbivory and fire $(p=0.0002)$ (Table 1). Highest species richness was associated with areas exposed to herbivory (Figure 4), although species richness in the control site (i.e. open, no fire) and the partially fenced treatment without fire was significantly higher compared to the fully fenced treatment with fire. Species richness in the partially fenced site with fire was, however, not significantly higher than the full exclosure treatments (Tukey: $p>0.05$ ).

Shannon-Wiener diversity index values showed no significant variation across the five combinations of herbivory and fire $(p=0.4)$ (Table 1).

\section{Discussion}

The effect of herbivore exclusion on total herbaceous biomass has been shown to be lower in the sodic zone than elsewhere in the riparian zone (Jacobs \& Naiman 2008). This phenomenon could be attributed to the drier conditions prevailing in the sodic zone throughout the year, as well as the shallow surface soils and relative impenetrability, making herbaceous species establishment and growth even more challenging. As would be expected, the exclusion of herbivores from the sodic zone lead to herbaceous biomass increases. The biomass range of $2500 \mathrm{~kg} / \mathrm{ha}-2900 \mathrm{~kg} / \mathrm{ha}$ (Figure 3) in the full exclosure is unusually high for sodic sites in semi-arid savanna ecosystems, because sodic soil is usually sparsely vegetated

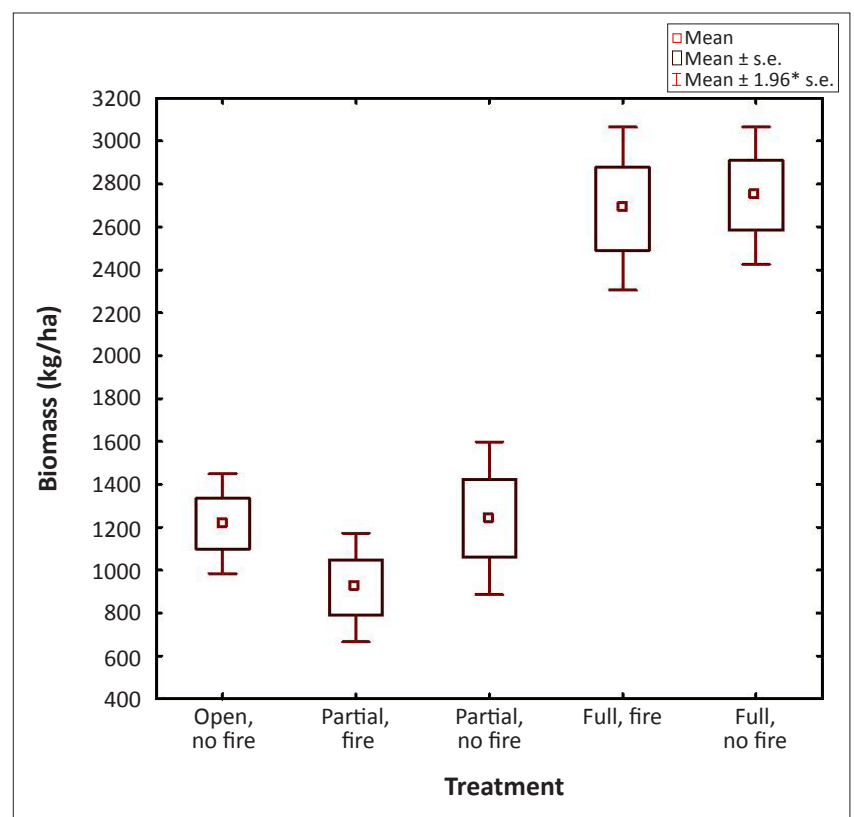

$\pm 1.96^{*}$, standard deviations of the mean; s.e., standard error.

FIGURE 3: Mean biomass ( $p<0.0001)$ across fire and herbivory treatments in the sodic zone of the Kruger National Park.

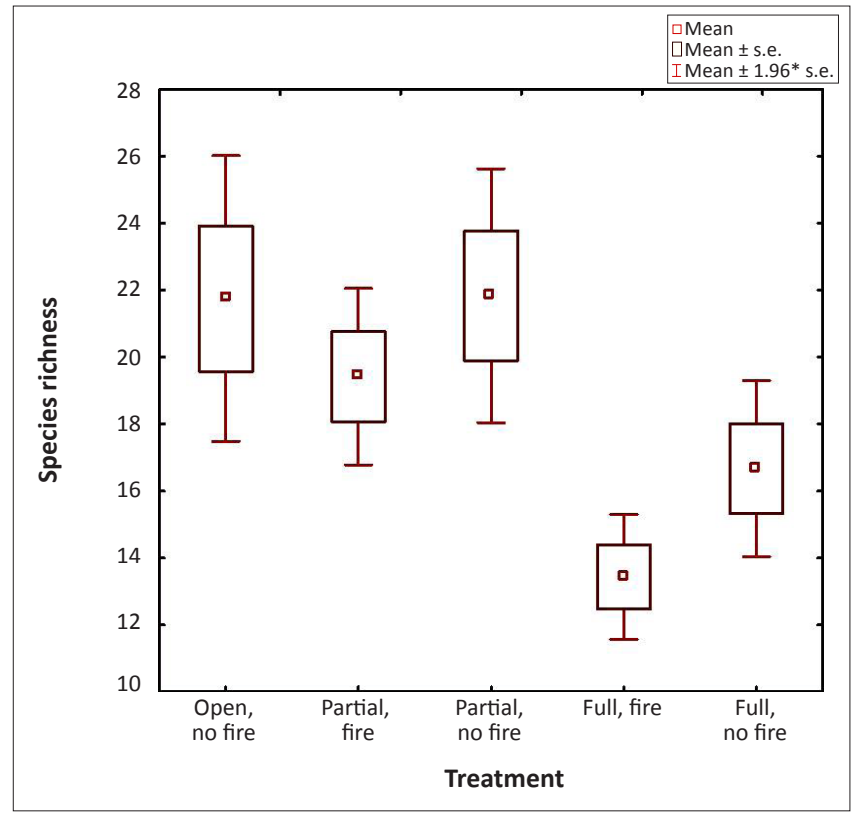

$\pm 1.96 *$, standard deviations of the mean; s.e., standard error.

FIGURE 4: Mean species richness $(p=0.0002)$ across fire and herbivory treatments in the sodic zone of the Kruger National Park.

and therefore associated with land degradation and gully formation that can become self-reinforcing as a result of its 
susceptibility to sheet erosion (Khomo \& Rogers 2005). The exclusion of herbivores, however, brings forth a gradual improvement in soil surface conditions, which re-establishes the predominance of topsoil water and allows for an increase in the biomass of grasses (Walker et al. 1981).

Furthermore, herbivory reduces biomass and canopy cover of certain plants and promotes spatial heterogeneity (Jacobs \& Naiman 2008). Sodic zones are favoured as forage patches by large herbivores, which gain essential nutrients from the herbaceous species growing there. The total exclusion of these herbivores from savanna riparian zones leads to a loss of game paths, feeding patches and wallows, causing a reduction in plant community heterogeneity (Jacobs \& Naiman 2008). According to Bakker, Blair and Knapp (2003), this heterogeneity, caused by different patches with long and short biomass, is thought to enhance the coexistence of a greater number of herbaceous species, hence boosting species richness. Although Jacobs and Naiman (2008) found no consistent effects of increasing biomass on species richness in the drier sodic zone after 4 years of herbivory exclusion (i.e. 2004/2005), our results indicated that the significantly higher biomass in the absence of herbivory seemed to suppress species richness after 10 years of herbivory exclusion. Highest species richness was associated with areas exposed to herbivory (Figure 4), thus areas where plant community heterogeneity was highest.

No significant variation in species diversity could be confirmed. As the Shannon-Wiener index of species diversity acknowledges the abundance of individual species, it could be expected that variation in species diversity is less perceptible than species richness. The sodic zone, in particular, is often dominated by few forb species that are well adapted to harsh conditions. Jacobs and Naiman (2008) reported that the succulent forb, Trianthema salsoides, contributed to a substantial proportion of the forb biomass in 2003-2004. Although T. salsoides was still prevalent in the 2010 data set, it was replaced as a dominant forb species by Achyranthes aspera. Dominance by a single species reduces the evenness of the sodic zone ecosystem, hence suppressing diversity. Lowest species richness was recorded in areas where herbivores were excluded. This is in accordance with Oba, Vetaas and Stenseth (2001) who suggested that long-term exclusion of herbivores may not necessarily have an increasing effect on species diversity and richness. The dynamic character of the vegetation in the sodic zone ecosystem therefore results in less predictable temporal changes in herbaceous species diversity.

\section{Conclusion}

In contradiction with the 'intermediate disturbance hypothesis', which suggests that highest diversity is maintained at intermediate levels of disturbance (Begon et al. 2006), highest species richness was associated with highest disturbance (i.e. open treatment). Increasing biomass as a result of the absence of herbivory suppresses the richness of herbaceous species in the sodic zone, although species

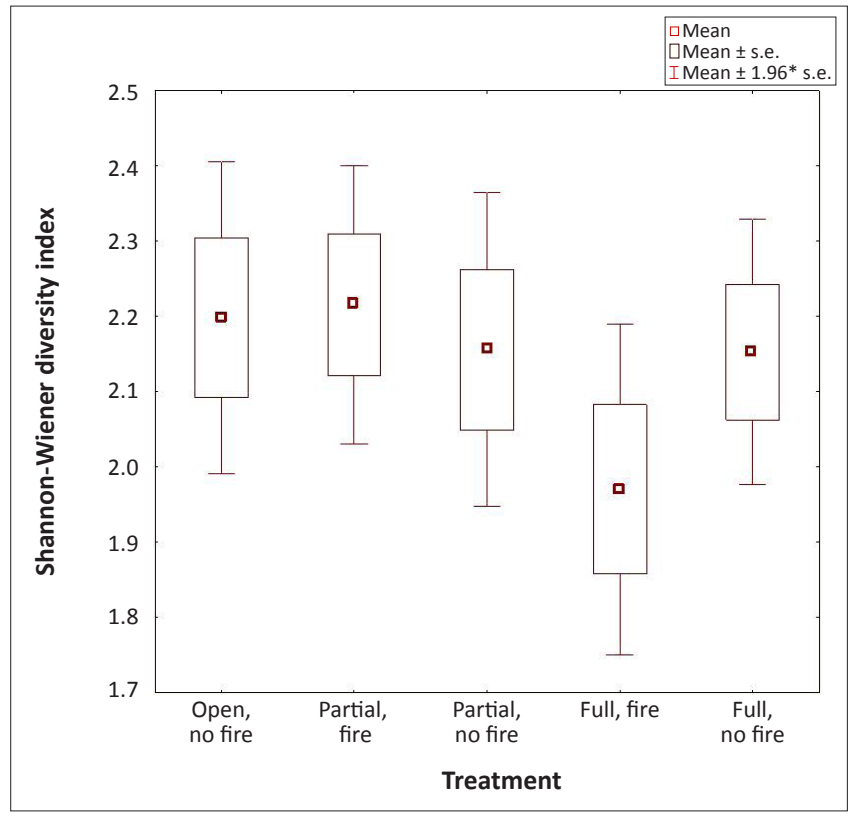

$\pm 1.96^{*}$, standard deviations of the mean; s.e., standard error.

FIGURE 5: Mean Shannon-Wiener diversity index values $(p=0.4)$ across fire and herbivory treatments in the sodic zone of the Kruger National Park.

richness is even lower in its combined effect of fire treatment. However, whilst species diversity patterns showed no significant differences across the treatments, lowest diversity was also measured in the absence of herbivory, but with fire treatment. It is therefore inferred that, although sodic patches are often associated with overgrazed, trampled vegetation, herbivores play an important role in the maintenance of species richness and diversity in these nutrient hotspots. Although statistically not significant, fire seems to suppress diversity and richness of the herbaceous layer in the sodic riparian zone. Floristic monitoring over a larger time scale under similar conditions is however required to support these premature results.

The combined assemblage of herbivores with (open treatment), or without (partial treatment) elephants, has the largest reduction in herbaceous standing biomass within the sodic zone of the Nkuhlu exclosures. Herbivory is suggested to be the primary driver of herbaceous vegetation dynamics in the sodic zone along the Sabie River, whether elephants are being included (open treatment) or excluded (partial treatment). Whilst suppressing standing biomass, herbivory maintains higher levels of herbaceous species richness. Fire, however, is suggested to be a secondary driver within the herbivory treatments, because it seems to suppress both herbaceous species richness and standing biomass. Despite clear patterns, no significant variation or differences with regard to herbaceous species diversity could be detected across treatments, which necessitates further long-term monitoring of herbaceous vegetation at nutrient hotspots along the Sabie River.

As the conservation of total biodiversity is the mandate of South African National Parks (SANParks), these findings have direct implications for the management of sodic zones 
in the KNP. The exclusion of herbivores may alter ecosystem functioning, especially at smaller scales, by increasing biomass at the cost of herbaceous species richness. Herbivores play an essential role in the reduction of herbaceous plant competition, in that herbivores decrease grass biomass which, in turn, promotes herbaceous species richness because fast-growing grasses can no longer overtop and shade out forbs. Herbivores are therefore considered imperative in the maintenance of species richness and diversity and ecosystem functioning in African savanna ecosystems, especially in sodic zones.

\section{Acknowledgements}

The authors would like to acknowledge SANParks for general logistical support. We are also grateful to the Research Unit: Environmental Sciences and Management, North-West University for financial support. In addition, our appreciation goes to Thomas Rikonibe for assistance and protection in the field, as well as Philip Ayres, Hannes Myburgh and Pieter Kloppers, who provided valuable assistance with field surveys.

\section{Competing interests}

The authors declare that they have no financial or personal relationships which may have inappropriately influenced them in writing this article.

\section{Authors' contributions}

H.v.C. (North-West University) was a post-graduate student who collected, analysed and reported the data, whilst F.S. (North-West University) was the project leader and supervisor to H.v.C. and was responsible for project design, data collection, analyses and reporting of data. S.J.S. (NorthWest University) made contributions in data sampling and reporting, whilst also fulfilling the role of co-supervisor. H.v.C., F.S. and S.J.S. wrote the manuscript.

\section{References}

Archibald, S., Bond, W.J., Stock, W.D. \& Fairbanks, D.H.K., 2005, 'Shaping the landscape: Fire-grazer interactions in an African savanna', Ecological Applications 15, 96-109. http://dx.doi.org/10.1890/03-5210
Bakker, C., Blair, J.M. \& Knapp, A.K., 2003, 'Does resource availability, resource heterogeneity or species turnover mediate changes in plant species richness in grazed grasslands?', Oecologia 137, 685-391. http://dx.doi.org/10.1007/s00442grazed grasslands?', Oecolog

Begon, M., Townsend, C.R. \& Harper, J.L., 2006, Ecology from individuals to ecosystems, Blackwell Publishing, Melbourne.

Davis, J.G., Waskom, R.M. \& Bauder, T.A., 2012, Managing sodic soils, viewed 11 September 2012, from http://www.ext.colostate.edu/pubs/crops/00504.html

Du Toit, J., Rogers, K.H. \& Biggs, H.C., 2003, The Kruger experience: Ecology and management of savanna heterogeneity, Island Press, Washington, DC.

Dye, P.J. \& Walker, B.H., 1980, 'Vegetation-environment relations on sodic soils of Zimbabwe Rhodesia', Journal of Ecology 68, 589-606. http://dx.doi. org $/ 10.2307 / 2259424$

Germishuizen, G. \& Meyer, N.L. (eds.), 2003, 'Plants of southern Africa: An annotated checklist', Strelitzia 14, South African National Botanical Institute, Pretoria.

Grant, C.C. \& Scholes, M.C., 2006, 'The importance of nutrient hot-spots in the conservation and management of large wild mammalian herbivores in semi-arid savannas', Biological Conservation 130, 426-437. http://dx.doi.org/10.1016/j. biocon.2006.01.004

Jacobs, S.M. \& Naiman, R.J., 2008, 'Large African herbivores decrease herbaceous plant biomass while increasing plant species richness in a semi-arid savanna
toposequence', Journal of Arid Environments 72, 891-903. http://dx.doi. org/10.1016/j.jaridenv.2007.11.015

Keller, B.E.M., 2002, 'Plant diversity in Lythrum, Phragmites, and Typha marshes, Massachusetts, USA', Wetlands Ecology and Management 8, 391-401. http:// dx.doi.org/10.1023/A:1026505817409

Khomo, L.M. \& Rogers, K.H., 2005, 'Proposed mechanism for the origin of sodic patches in Kruger National Park, South Africa', African Journal of Ecology 43, 2934. http://dx.doi.org/10.1111/j.1365-2028.2004.00532.x

Mucina, L. \& Rutherford, M.C. (eds.), 2006, The vegetation of South Africa, Lesotho and Swaziland, South African National Biodiversity Institute, Pretoria.

Oba, G., Vetaas, O.R. \& Stenseth, N.C., 2001, 'Relationships between biomass and plant species richness in arid-zone grazing lands', Journal of Applied Ecology 38 836-845. http://dx.doi.org/10.1046/j.1365-2664.2001.00638.x

O'Keefe, T. \& Alard, G., 2002, 'Effects of herbivores and fire on riparian and upland savanna ecosystems', Unpublished report on field operations manual for herbivore and fire exclosures on the Sabie and Letaba Rivers in the Kruger National Park.

Scogings, P.F., 2011, 'Stem growth of woody species at the Nkuhlu exclosures, Kruger National Park: 2006-2010', Koedoe 53(1), Art. \#1035, 8 pages. http://dx.doi. org/10.4102/koedoe.v53i1.1035

Scogings, P.F., Johansson, T., Hijáltén, J. \& Kruger, J., 2012, 'Response of woody vegetation to exclusion of large herbivores in semi-arid savannas', Austral Ecology 37, 56-66. http://dx.doi.org/10.1111/j.1442-9993.2011.02249.x

Siebert, F. \& Eckhardt, H.C., 2008, 'The vegetation and floristics of the Nkuhlu exclosures, Kruger National Park', Koedoe 50, 126-144. http://dx.doi.org/10.4102/ koedoe.v50i1.138

Statistica version 9.1, 2010, StatSoft, Inc., Tulsa.

Tarasoff, C.S., Mallory-Smith, C.A. \& Ball, D.A., 2007, 'Comparative plant responses of Puccinellia distans and Puccinnellia nuttalliana to sodic versus normal soil types', Journal of Arid Environments 70, 403-417. http://dx.doi.org/10.1016/j. jaridenv.2007.01.008

Van Wyk, P. \& Fairall, N., 1969, 'The influence of the African elephant on the vegetation of the Kruger National Park', Koedoe 12(1), 57-76. http://dx.doi.org/10.4102/ koedoe.v12i1.747

Venter, F.J., 1990, 'A classification of land use for management planning in the Kruger National Park', PhD thesis, Department of Geography, University of South Africa.

Walker, B.H., Ludwig, D., Holling, C.S. \& Peterman, R.M., 1981, 'Stability of semiarid savanna grazing systems', Journal of Ecology 69, 473-498. http://dx.doi. arid savanna grazing
org/10.2307/2259679

Zambatis, N., Zacharias, P.J.K., Morris, C.D. \& Derry, J.F., 2006, 'Re-evaluation of the disc pasture meter calibration for the Kruger National Park, South Africa', African Journal of Range and Forage Science 23(2), 85-97. http://dx.doi. org/10.2989/10220110609485891 